\title{
Fetal growth restriction: adaptations and consequences*
}

\author{
I. Caroline McMillen ${ }^{1}$, Michael B. Adams ${ }^{1}$, Jacob T. Ross ${ }^{4}$, \\ Catherine L. Coulter ${ }^{1}$, Guiseppe Simonetta ${ }^{3}$, Julie A. Owens ${ }^{1}$, \\ Jeffrey S. Robinson ${ }^{2}$ and Lisa J. Edwards ${ }^{1}$ \\ Departments of ${ }^{1}$ Physiology and ${ }^{2}$ Obstetrics and Gynaecology, Adelaide University, SA 5005, \\ Australia; ${ }^{3}$ School of Physiology and Pharmacology, University of New South Wales, Sydney, \\ NSW 2052, Australia; and ${ }^{4}$ Perinatal Research Centre, University of Alberta, Edmonton, \\ Alberta, Canada
}

\begin{abstract}
A range of pathophysiological factors can result in a perturbation or restriction of fetal growth, and the cardiovascular, neuroendocrine and metabolic adaptations of the fetus to these stimuli will depend on their nature, timing and intensity. The critical importance of these physiological adaptations for both immediate survival and long-term health outcomes has provided an impetus for experimental studies of the nature and consequences of specific fetal adaptations to a poor intrauterine environment. This review summarizes data from recent studies that have focused on the responses of the fetal cardiovascular, sympathoadrenal, hypothalamo-pituitary-adrenal and renin-angiotensin systems to experimental restriction of placental function in the sheep and discusses the consequences of these adaptations for fetal, neonatal and adult health.
\end{abstract}

Intrauterine growth restriction is a relatively common condition that results in disproportionately high perinatal morbidity and mortality (Knutzen and Sher, 1982; Newton et al., 1987). Intrauterine growth restriction may be classified clinically on the basis of a birth weight below the tenth percentile for gestational age or, in experimental studies, as a fetal body weight below two standard deviations of the mean of the relevant study population. A range of pathophysiological factors can result in a perturbation or restriction of fetal growth, including gene defects, chromosomal abnormalities, poor placental function, maternal smoking, maternal alcohol or drug abuse and altered maternal substrate concentrations (Robinson et al., 1994). The specific physiological adaptations of the fetus to an adverse intrauterine environment, including restriction of its growth rate, may depend on the nature, timing and intensity of such extra- and intrauterine challenges. It is clear that the physiological adaptations of the fetus to its suboptimal intrauterine environment are of critical importance in determining the health and survival of the fetus and newborn. Furthermore, a series of worldwide epidemiological studies (Barker et al., 1990; Barker, 1992, 1998; Huxley et al., 2000) has highlighted the potential importance of fetal adaptations to a poor intrauterine environment for longer term health outcomes. These studies have demonstrated that there are significant relationships

Email: caroline.mcmillen@adelaide.edu.au

*This article is based on a presentation given at the British Society of Animal Science symposium 'Early Regulation of Mammalian Development' held in Aberdeen in September 2000. between birth weight or birth phenotype and the relative risk of onset of ischaemic heart disease, hypertension and non-insulin-dependent diabetes. These associations are independent of adult lifestyle or adult size and are summarized in the hypothesis known as the 'fetal origins of adult disease' (Barker, 1998, 1999), in which it is proposed that the physiological, neuroendocrine or metabolic adaptations that enable the fetus to survive a period of intrauterine deprivation result in a permanent reprogramming of the developmental pattern of proliferation and differentiation events within key tissue and organ systems and pathological consequences in adult life (Barker, 1999). The critical importance of fetal adaptations for both immediate survival and long-term health outcomes has provided an impetus for experimental studies of the nature and consequences of specific fetal adaptations to a poor intrauterine environment. This review summarizes data from recent studies that have focused on the range of cardiovascular, neuroendocrine and metabolic adaptations the fetus makes in response to experimental restriction of placental function and discusses the consequences of these adaptations for fetal, neonatal and adult health.

\section{Experimental models of restriction of placental function}

The major substrates for mammalian fetal growth and development are oxygen, glucose, lactate and amino acids. Placental dysfunction resulting in a restriction of fetal substrate supply is a major cause of altered or reduced fetal growth (Robinson et al., 1994). Several different experimental 
approaches have been used to produce placental insufficiency with resultant fetal growth restriction in small and large animal models. The primary methods include a reduction in uterine blood flow by vascular occlusion or ligation in rats, guinea-pigs and sheep (Lafeber et al., 1985; Boyle et al., 1996), placental infarction by repetitive embolization in pregnant ewes (Clapp et al., 1981; Block et al., 1990; Murotsuki et al., 1997), or limitation of placental growth through surgical removal of most of the endometrial caruncles from the uterus of non-pregnant ewes before conception (Robinson et al., 1979). This procedure restricts the number of placental cotyledons formed, and subsequently limits placental and hence fetal growth. Several comprehensive reviews have summarized the effects of this experimental method of restriction of placental growth on oxygen and glucose delivery and consumption by the placenta and fetus (Owens et al., 1989; Robinson et al., 1994). Placentally restricted fetuses are chronically hypoxaemic, hypoglycaemic and have increased blood lactate concentrations and, usually, no change in fetal arterial pH (Owens et al., 1989; Robinson et al., 1994). The changes in fetal blood gas status and nutrient supply in placentally restricted sheep fetuses are similar to those measured in cordocentesis studies of human infants who are small for their gestational age (Economides et al., 1991).

\section{Placental restriction and fetal organ growth}

As is also the case in human intrauterine growth restriction (IUGR), experimental restriction of placental growth results in an asymmetrical pattern of fetal growth restriction whereby body weight is reduced to a greater extent than crown-rump length or girth (Robinson et al., 1994). We have analysed the pattern of relative fetal organ masses in a large cohort of placentally restricted sheep fetuses and control sheep fetuses between day 137 and day 147 of gestation. The placentally restricted cohort $(n=71)$ included animals that were or were not growth-restricted, depending on the extent of compensatory growth of the placenta, whereas the control cohort $(n=270)$ also included animals that were either normally grown or spontaneously growth restricted, for example twins. The analysis of fetal organ masses in such cohorts spanning a wide range of fetal body weights allowed comparisons to be made between the effects of spontaneous or experimental growth restriction on relative organ growth. It was also possible to determine from such analyses whether changes emerge in the growth patterns of specific organs at particular levels or thresholds of fetal growth restriction. We have found a significant inverse relationship between the relative mass of the fetal brain and fetal body weight, which is present across the full spectrum of fetal body weights from 1 to $6 \mathrm{~kg}$ (Fig. 1). The strength of this relationship indicates that brain growth is maintained through compensatory mechanisms across the entire weight range of both normally grown and growthrestricted sheep fetuses. The maintenance of brain mass appears to be of primary importance for all fetuses whether they are normally grown or growth-restricted, indicating

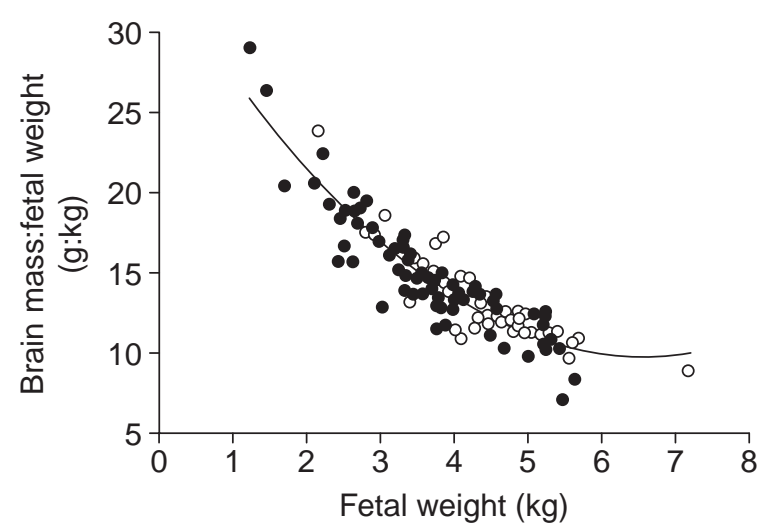

Fig. 1. Relationship between relative brain mass and fetal body weight in a cohort of normally grown $(O ; n=50)$ and placentally restricted $(0 ; n=74)$ sheep fetuses between day 137 and day 147 of gestation. The relative brain mass increased with decreasing fetal weight according to the equation: brain mass:fetal weight $=0.91$ (fetal weight $)^{2}-10.1$ (fetal weight $)+39.2\left(r^{2}=0.85, P<0.0001\right)$.

that, whereas compensatory mechanisms may maintain disproportionate brain growth in growth-restricted fetal lambs, similar physiological mechanisms must operate, albeit to a lesser extent, to ensure brain mass is maintained within an optimal range even in normoxaemic, apparently well grown animals. This pattern of fetal organ growth is dissimilar to that of other organs such as the kidney (Fig. 2). Fetal kidney growth occurs in proportion to body weight until the fetal body weight decreases below about $2 \mathrm{~kg}$, at which point fetal kidney mass is then maintained disproportionate to fetal body weight. In contrast to the fetal brain and kidney, there is a direct relationship between the relative mass of the fetal liver and fetal body weight, and the variation in the relative mass of the liver is less related to fetal body weight than is fetal brain or kidney mass (Fig. 3). Furthermore, there is only a decrease in relative liver mass once the fetal body weight decreases below about $3 \mathrm{~kg}$.

Thus, variations in the timing, intensity and duration of placental restriction of fetal substrate supply result in different fetal cardiovascular, neuroendocrine and metabolic adaptations and differential patterns of the relative growth of key fetal organs such as the brain and the liver as fetal body weight decreases. This variation in the fetal responses to a decreasing substrate supply may underpin the differences in the pattern of the associations between specific adult disease outcomes, such as high blood pressure or non-insulin-dependent diabetes mellitus (NIDDMS), and birth weight. Adult systolic blood pressure is reported to be inversely related to birth weight across the full birth weight ranges of normally grown and growthrestricted babies (Huxley et al., 2000). This finding is similar to the relationship found between the relative mass of the fetal brain and fetal body weight in our cohort of normally grown and growth-restricted sheep fetuses. In a systematic review of the association between systolic blood pressure and birth measurements other than birth weight, the most 


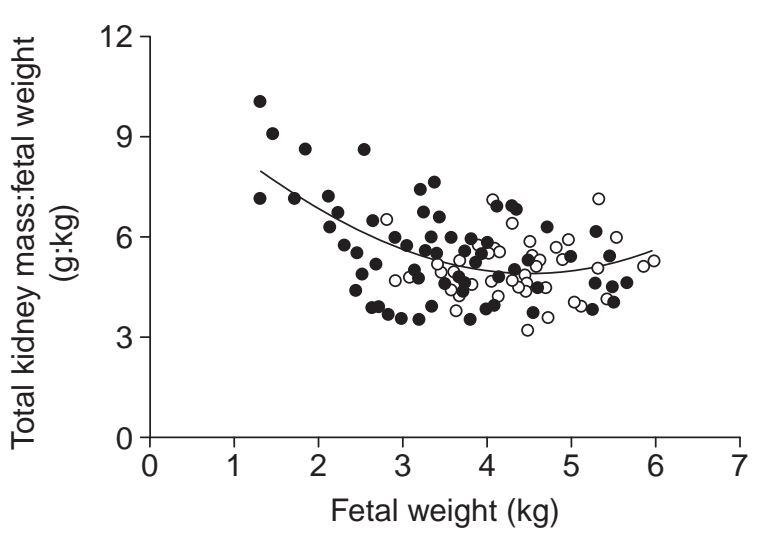

Fig. 2. Relationship between relative kidney mass and fetal body weight in a cohort of normally grown $(O ; n=49)$ and placentally restricted $(\mathbf{0} ; n=65)$ sheep fetuses between day 137 and day 147 of gestation. The relative kidney mass increased with decreasing fetal weight according to the equation: kidney mass:fetal weight $=0.31$ (fetal weight $)^{2}-2.77$ (fetal weight $)+11.13\left(r^{2}=0.27, P<0.0001\right)$.

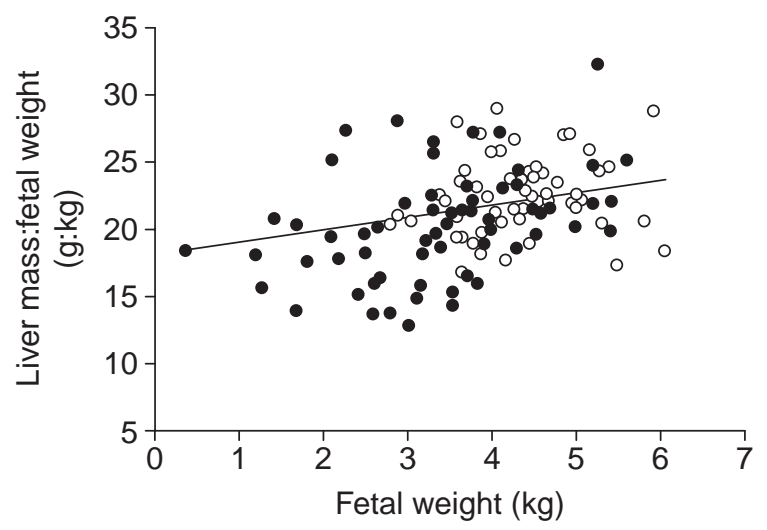

Fig. 3. Relationship between relative liver mass and fetal body weight in a cohort of normally grown $(\bigcirc ; n=57)$ and placentally restricted $(; n=65)$ sheep fetuses between day 137 and day 147 of gestation. The relative liver mass decreased with decreasing fetal weight according to the equation: liver mass:fetal weight $=-0.18$ (fetal weight $)^{2}+2.7$ (fetal weight $)+14.1\left(r^{2}=0.12, P<0.0001\right)$.

consistently reported finding was an inverse association between head circumference at birth and systolic blood pressure in later life (Huxley et al., 2000). One possibility is that the fetal cardiovascular and neuroendocrine adaptations that ensure that substrate delivery to the brain and hence brain growth are maintained at any given fetal weight underlie the emergence of the relationship between birth weight and systolic blood pressure in adult life.

\section{Fetal cardiovascular adaptations to placental restriction}

\section{Arterial blood pressure}

Although the fetal cardiovascular responses to acute episodes of hypoxaemia lasting several hours or fewer have been well documented (Giussani et al., 1994), there are fewer studies on the fetal cardiovascular responses to the imposition of chronic hypoxaemia, that is, periods of hypoxaemia extending across weeks or months. Murotsuki et al. (1997) reported a significant increase in fetal blood pressure in response to a 21 day period of embolization of the fetal placental circulation. However, there are no differences in mean arterial blood pressure between normally grown sheep fetuses and sheep fetuses chronically hypoxaemic and growth restricted after either restriction of placental growth or embolization of the uteroplacental vascular bed in late gestation (Llanos et al., 1980; Robinson et al., 1983; Walker et al., 1990). Edwards et al. (1999) found that although there was no difference in the mean arterial blood pressure between normally grown and placentally restricted sheep fetuses, there was a direct relationship between blood pressure and the mean gestational $\mathrm{pO}_{2}$ in control animals, which was not present in the placentally restricted group. Given that the sheep fetuses with higher mean gestational arterial $p \mathrm{O}_{2}$ values are also larger, it is possible that the higher mean blood pressure values in the normally grown sheep fetuses reflect an increased cardiac output. Alternatively, it may be that, as the fetus grows in late gestation, fetal vascularity does not increase in parallel with fetal size, resulting in increased fetal peripheral vascular resistance and fetal arterial blood pressure. Daniel et al. (1996a) also found a positive relationship between arterial blood pressure and the fetal:maternal weight ratio in a combined group of control sheep fetuses and sheep fetuses in which mild growth restriction and hypoxaemia was produced by withdrawal of $25 \mathrm{ml}$ maternal blood per day throughout the second half of pregnancy. Thus, fetal hypotension may be a good indicator of mild but not moderate or severe growth restriction.

The loss of the relationship between arterial blood pressure and $\mathrm{pO}_{2}$ in moderately or severely growthrestricted sheep fetuses may be a consequence of a reduction in arteriolar branching in key fetal circulatory regions due to an adverse effect of chronic hypoxaemia on angiogenesis. Alternatively, the loss of this relationship may be a consequence of an increase in circulating vasoactive hormones secreted in response to a decrease in fetal oxygenation and nutrient status, for example noradrenaline, angiotensin II and cortisol. During acute hypoxaemia, blood flow to the brain, heart and adrenal glands is increased and blood flow to the gastrointestinal, renal and peripheral vascular beds decreases (Jensen et al., 1987a,b; Yaffe et al., 1987; Jansen et al., 1989; Giussani et al., 1993). This redistribution of fetal cardiac output is also maintained with prolonged hypoxaemia in pregnancy, presumably as a consequence of the action of vasoactive hormones (Bocking et al., 1988; Rurak et al., 1990).

Clearly, the redistribution of the fetal cardiac output as an adaptation to chronic placental restriction is critically important for the maintenance of the relative growth and optimal function of key fetal organs such as the heart and brain. However, redistribution of cardiac output away from 
particular regional circulations in late gestation may have some negative consequences in the immediate newborn period. Doppler ultrasound studies have shown that on the first day of postnatal life, both superior mesenteric artery and coeliac axis blood flow velocity are reduced in growthrestricted infants, when compared with appropriately grown, weight matched and gestation matched control infants (Kempley et al., 1991). Reduced blood flow velocity was found only in those growth-restricted infants who showed evidence in Doppler ultrasound studies of fetal hypoxia as indicated by absence of end-diastolic flow in the fetal aorta. This difference in blood flow velocity persisted for about a week of postnatal life and, after this age, the superior mesenteric blood flow velocity was the same in IUGR infants as that found in appropriately grown infants on the first day of life. The differences in blood flow velocity during the first week of life could not be explained by differences in blood pressure or arterial oxygen tension at the time of measurement. Therefore, Kempley et al. (1991) suggested that the differences in visceral blood flow velocity were due to a persistently increased intestinal vascular resistance that was 'programmed' during fetal life. Therefore, the increased risk of necrotizing enterocolitis in those growth-restricted infants with absent end-diastolic flow in the aorta in fetal life may be a result of hypoxaemicischaemic tissue damage occurring in utero, or a consequence of increased vascular resistance persisting after delivery.

We have found that systolic blood pressure in a cohort $(n=35)$ of normally grown and placentally restricted lambs at 1 year of age is inversely related to the weight or ponderal index of the lamb at birth in an analysis that adjusts for current shoulder height. Maternal undernutrition during the first 30 days of pregnancy in ewes results in lower blood pressure in the fetus during later gestation but an increased blood pressure in postnatal life (Hoet and Hanson, 1999). Thus, it appears that the timing, type and duration of fetal substrate restriction are each important in determining the specific nature of the fetal neuroendocrine and cardiovascular adaptive responses and their interactions in determining long-term consequences. The following sections review the impact of placental restriction on the fetal sympathoadrenal, pituitary-adrenal and the reninangiotensin systems and the importance of these fetal neuroendocrine adaptations for short-term survival and longer-term adverse health outcomes such as hypertension.

\section{Placental restriction and the fetal sympathoadrenal system}

\section{Adrenaline and the fetal adrenal medulla}

Although plasma adrenaline concentrations are higher in placentally restricted sheep fetuses, the relationship between plasma adrenaline and arterial $p \mathrm{O}_{2}$ is different in control and in placentally restricted animals. In control animals, there is an inverse relationship between adrenaline and arterial $p \mathrm{O}_{2}$, such that a decrease in arterial $p \mathrm{O}_{2}$ results in an increase in circulating adrenaline concentrations (Simonetta et al., 1997). In contrast, in the placentally restricted group, a decrease in arterial $\mathrm{pO}_{2}$ is associated with a relative suppression, rather than a stimulation, of plasma adrenaline concentrations. Thus, factors other than arterial $\mathrm{pO}_{2}$ are important for maintaining high basal adrenaline concentrations in the circulation of the placentally restricted sheep fetuses. Although the fetal adrenal gland is the source of increased circulating catecholamines during acute fetal hypoxaemia (Jones et al., 1988), the impact of chronic hypoxaemia on the fetal adrenomedullary chromaffin cells has been less well defined. Immunostaining for the catecholamine synthetic enzymes dopamine $\beta$-hydroxylase and phenylethanolamine $\mathrm{N}$-methyltransferase (PNMT) is significantly suppressed in the adrenal medulla of the placentally restricted fetus at as early as day 90 of gestation (Coulter et al., 1998). Furthermore, placental restriction is associated with a decrease in the adrenal concentrations of PNMT mRNA of approximately $70 \%$ and a decrease in the adrenomedullary area stained positive with anti-PNMT of approximately 50\% at about day 140 of gestation (Adams et al., 1998). There is also a positive correlation between mean arterial $\mathrm{pO}_{2}$ and the amount of adrenal PNMT mRNA during late gestation (Fig. 4). The direct relationship between PNMT mRNA expression and mean gestational arterial $p \mathrm{O}_{2}$ in individual sheep fetuses indicates that low arterial $p_{2}$ acts by either neurogenic or non-neurogenic mechanisms to suppress PNMT synthesis. Placental restriction had no effect on tyrosine hydroxylase mRNA concentrations in the fetal adrenal. Thus, in contrast to acute hypoxaemia, placental restriction and the associated chronic hypoxaemia result in a suppression of the adrenaline synthetic capacity of the fetal adrenal medulla. Fetal growth restriction induced by single umbilical artery ligation in sheep (Oyama et al., 1992) results in a diminished fetal adrenaline response to delivery, and growth-restricted rat pups have impaired adrenaline secretory responses to acute hypoxia after birth (Shaul et al., 1989). Therefore, the impact of intrauterine hypoxaemia on adrenaline synthesis and secretion may have significant physiological consequences before, during and immediately after birth.

\section{Noradrenaline and the sympathetic nervous system}

Acute episodes of intrauterine hypoxia or asphyxia stimulate an increase in the plasma concentrations of noradrenaline and adrenaline in sheep fetuses during late gestation. The increase in circulating catecholamines is important in the initiation and co-ordination of a range of fetal physiological responses to hypoxic stress (Giussani et al., 1994). Plasma noradrenaline concentrations were significantly higher in chronically hypoxaemic, growthrestricted sheep fetuses than in control sheep fetuses between day 110 and day 140 of gestation (Simonetta et al., 1997). Covariate analysis demonstrated that at any given arterial $\mathrm{pH}$ value, plasma noradrenaline concentrations 


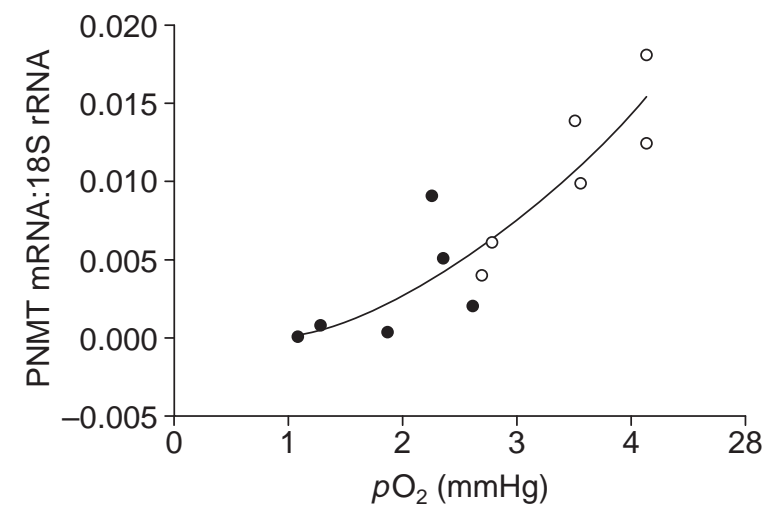

Fig. 4. Relationship ( $r=0.88, P<0.0005)$ between adrenal phenylethanolamine $\mathrm{N}$-methyltransferase (PNMT) mRNA:18S rRNA expression with mean gestational arterial $\mathrm{pO}_{2}$ in control $(O ; n=6)$ and placentally restricted $(; n=6)$ sheep fetuses at days $140-141$ of gestation. (Redrawn from Adams et al., 1998.)

were about $2.9 \mathrm{pmol} \mathrm{ml}^{-1}$ higher in the placentally restricted than in the control group. For every $1 \mathrm{mmHg}$ decrease in arterial $p \mathrm{O}_{2}$, noradrenaline increased by $0.4 \mathrm{pmol} \mathrm{ml}^{-1}$ during basal conditions in both the placentally restricted and control groups. Throughout late gestation, the prevailing mean arterial $\mathrm{pO}_{2}$ was approximately $8 \mathrm{mmHg}$ lower in the placentally restricted group than in the control group and, therefore, would account for the difference in noradrenaline concentrations of about $3.2 \mathrm{pmol} \mathrm{ml}^{-1}$ between the groups (Simonetta et al., 1997). Therefore, it appears that chronic hypoxaemia is the major factor contributing to the increase in circulating noradrenaline concentrations in the placentally restricted group in late gestation. Plasma noradrenaline concentrations were also doubled in sheep fetuses made chronically hypoxaemic after a 10 day period of fetal placental embolization using repeated injections of non-radioactive microspheres (Gagnon et al., 1994). The source of the increase in circulating noradrenaline concentrations during chronic or intermittent restriction of placental function may be either increased secretion from the fetal adrenal medulla, extra adrenal chromaffin tissue or sympathetic neurones. Intrafetal infusion of tyramine, which acts to displace noradrenaline from catecholamine-containing vesicles within postganglionic sympathetic neurones, results in a significantly greater increase in plasma noradrenaline in placentally restricted sheep than it does in control sheep fetuses (Simonetta et al., 1997). However, when these noradrenaline responses were expressed in relation to basal circulating concentrations, there was no difference in the fold changes in noradrenaline in response to tyramine between the placentally restricted and control animals. The proportional relationship between basal and stimulated noradrenaline concentrations in the two groups indicates that the increased basal noradrenaline concentration is derived from sympathetic nerve terminals in the placentally restricted group. One possibility is that placental restriction and the presence of chronic hypoxaemia throughout late gestation is a stimulus for hyperinnervation of fetal vessels and tissues by sympathetic, postganglionic neurones. Alternatively, low $\mathrm{pO}_{2}$, or other factors associated with placental restriction, reflexly stimulate catecholamine synthesis and secretion in developing sympathetic neurones. Although the vasoconstrictor responses to acute hypoxaemia and asphyxia are reduced by sympathectomy and $\alpha$ adrenergic blockade (Jones et al., 1988; Giussani et al., 1994), it is not yet clear whether the redistribution of fetal cardiac output during chronic hypoxaemia is dependent on the increase in fetal sympathetic activity. One possibility is that cerebral blood flow, and therefore brain growth, is maintained by the precise relationship between the prevailing arterial $p \mathrm{O}_{2}$ and plasma noradrenaline concentrations in both normally grown and growth-restricted fetuses.

\section{Postnatal consequences of adaptations of the fetal sympathoadrenal system to placental restriction}

Placental restriction results in an increase in the functional capacity of the sympathetic nervous system with an apparent concurrent suppression in the functional capacity of the adrenal medulla. Although basal adrenaline concentrations are maintained, adrenaline responses to acute stressors, such as neonatal hypoglycaemia, may be impaired in the growth-restricted fetus and newborn. It is also unknown whether changes in sympathetic 'tone' within particular regional circulations are maintained into adult life after a period of intrauterine growth restriction. In a study of 449 men and women born in Preston, UK, a direct relationship was found between adult pulse rate and birth weight (Flanagan et al., 1999). Pulse rate decreased progressively from 76 beats $\mathrm{min}^{-1}$ in subjects who weighed $2.5 \mathrm{~kg}$ or less at birth to 71 beats $\mathrm{min}^{-1}$ in those who weighed $3.3 \mathrm{~kg}$ or more (a 2.7 beat $\mathrm{min}^{-1}$ decline in pulse rate per $\mathrm{kg}$ increase in birth weight). This association was independent of current body mass index, waist:hip ratio and of potential confounding variables including smoking, alcohol consumption and social class. The authors of this study concluded that, although resting pulse rate is an imperfect index of activity of the sympathetic nervous system (SNS), these findings were consistent with the hypothesis that increased SNS activity established in utero is one mechanism linking small size at birth with other adverse outcomes such as high blood pressure or insulin resistance syndrome in adult life.

\section{Placental restriction and the fetal hypothalamo-pituitary-adrenal (HPA) axis}

There is growing interest in the consequences of premature exposure of the fetus to excess glucocorticoids, occurring after either therapeutic administration of synthetic glucocorticoids to women in threatened preterm labour, as a consequence of acute maternal stress, or activation of 
the fetal hypothalamo-pituitary-adrenal (HPA) axis by intrauterine substrate deprivation (Seckl et al., 1999, 2000). Maternal undernutrition during pregnancy in rats results in high blood pressure in the offspring and this effect is prevented by the inhibition of maternal corticosterone biosynthesis during pregnancy (Langley-Evans et al., 1996). Treatment of pregnant rats with the synthetic glucocorticoid dexamethasone (Levitt et al., 1996) or with carbenoxolone, an inhibitor of the placental enzyme that metabolizes corticosterone to the inert 11-dehydrocorticosterone (Langley-Evans, 1997), results in a lower mean birth weight, persistent increased arterial blood pressure and fasting hyperglycaemia in the adult offspring. Therefore, overexposure of the fetus to excess glucocorticoids may be implicated in the association between fetal growth restriction and the programming of adult cardiovascular and metabolic diseases. There has been less experimental evidence on the impact of placental restriction or maternal undernutrition on the fetal HPA axis in a longer gestation species, such as sheep or humans, or on the role that the endogenous fetal cortisol response to intrauterine substrate deprivation plays in postnatal programming in these species.

The relative growth of the fetal adrenal is increased (Fig. 5) and fetal plasma concentrations of cortisol are higher in placentally restricted animals than in their normally grown counterparts after day 127 of gestation (Phillips et al., 1996). The late gestation increase in fetal cortisol occurs in the absence of any change in fetal adrenocorticotrophic hormone $(\mathrm{ACTH})$ concentrations and there is a significant decrease in the pituitary mRNA concentrations of the ACTH precursor pro-opiomelanocortin (POMC) in placentally restricted fetuses when compared with controls (Phillips et al., 1996). An increase in fetal cortisol is a consistent response to prolonged or repeated fetal hypoxaemia in late gestation and this increase is not always associated with an increase in fetal ACTH. In experiments in which hypoxaemia was induced in sheep fetuses by a reduction in utero-placental blood flow for $24 \mathrm{~h}$, fetal ACTH concentrations were increased at only $2 \mathrm{~h}$ after the onset of the hypoxaemia and then returned to baseline values (Sug Tang et al., 1992). In contrast, fetal cortisol concentrations were increased by $2 \mathrm{~h}$ after the onset of hypoxaemia and remained high throughout the $24 \mathrm{~h}$ period. Cordocentesis studies have also found that plasma cortisol concentrations were higher and plasma ACTH concentrations lower in IUGR human fetuses than in normally grown fetuses at weeks 18-38 of gestation (Economides et al., 1988). In contrast to these studies, fetal ACTH concentrations remained high during a 20 day period in which the fetal placental circulation was repeatedly embolized (Murotsuki et al., 1996). Thus, the fetal HPA axis may adapt to the effects of prolonged or sustained hypoxaemia, whereas repeated hypoxaemic episodes, such as those experienced during repeated placental embolization, may maintain stimulation of the fetal HPA axis.

It is possible that the HPA axis in the growth-restricted fetus is operating at a new central set point, which results

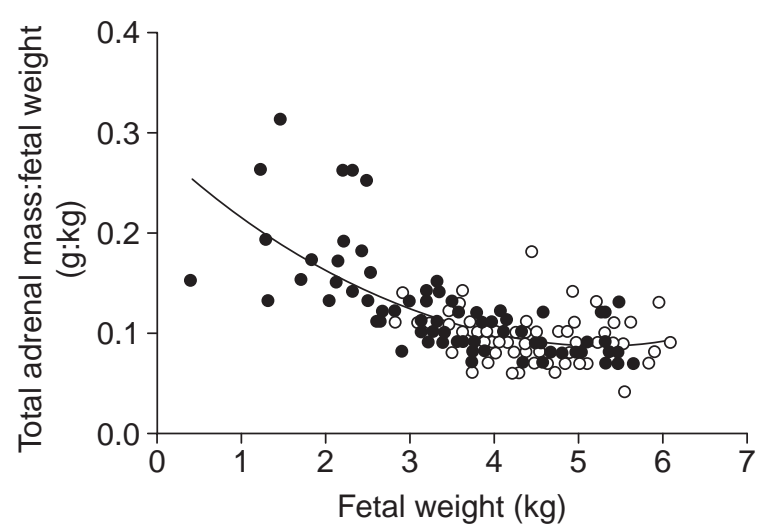

Fig. 5. Relationship between relative adrenal mass and fetal body weight in a cohort of normally grown $(\bigcirc ; n=108)$ and placentally restricted $(0 ; n=74)$ sheep fetuses between day 137 and day 147 of gestation. The relative adrenal mass increased with decreasing fetal weight according to the equation: adrenal mass:fetal weight $=10.3$ (fetal weight $)^{2}-101$ (fetal weight $)+335\left(r^{2}=0.50, P<0.0001\right)$.

in maintained ACTH concentrations, increased adrenal sensitivity to ACTH and increased adrenal mass and corticosteroid output. However, there is a decrease, rather than an increase, in the adrenal expression of ACTH receptor mRNA in growth-restricted sheep fetuses (Ross et al., 2000). Another possibility is that there are factors other than ACTH in the placentally restricted group that stimulate adrenal cortisol synthesis and secretion. This contention is supported by the observation that placental restriction resulted in a relative increase in adrenal cytochrome $\mathrm{P} 450$ side chain cleavage (CYP11A1) mRNA in the absence of changes in the adrenal mRNA concentrations of steroidogenic enzymes known to be responsive to ACTH stimulation, that is, cytochrome P450 17 $\alpha$-hydroxylase (CYP17), cytochrome P450 21-hydroxylase (CYP21A1) and 3ßhydroxysteroid dehydrogenase $/ \Delta^{5}, \Delta^{4}$-isomerase (3ß-HSD) (Ross et al., 2000). Braems et al. (1998) reported an increase in the adrenal mRNA concentrations of CYP11A1, 3BHSD and CYP21A1, but not CYP17, after $48 \mathrm{~h}$ of fetal hypoxaemia. These data indicate that factors other than $\mathrm{ACTH}$, for example, placental prostaglandin $E_{2}$ or angiotensin II, may stimulate an increase in adrenal steroidogenesis in the chronically hypoxaemic fetus.

Increases in circulating cortisol may play an important role in the adaptation of the fetal cardiovascular system to intrauterine growth restriction (Phillips et al., 1996; Langley-Evans, 1997; Edwards et al., 1999; Hoet and Hanson, 1999). Intrafetal infusion of either cortisol or the synthetic glucocorticoids betamethasone and dexamethasone for periods of up to $48 \mathrm{~h}$ at about days 120-130 of gestation results in an increase in fetal femoral vascular resistance (Derks et al., 1997) and in arterial blood pressure (Wood et al., 1987; Tangalakis et al., 1992; Anwar et al., 1999). Infusion of cortisol for 6 days after bilateral fetal adrenalectomy also restored fetal arterial blood pressure to 
values measured in intact fetuses at about day 125 of gestation (Unno et al., 1999). Furthermore, blood pressure responses to increasing doses of angiotensin II, but not noradrenaline, were increased in sheep fetuses after infusion of cortisol for $48 \mathrm{~h}$ at about day 125 of gestation (Tangalakis et al., 1992). Intrafetal infusion of cortisol also results in an increased expression of angiotensin II type I (AT1) receptor mRNA within the fetal heart (right and left atrium and right ventricle) (Segar et al., 1995) and there is a greater hypotensive effect after blockade of AT1 receptors in sheep fetuses that have been infused with cortisol (Forhead et al., 2000). Thus, there is evidence that increased exposure to cortisol during fetal life results in an increased sensitivity to the vasoconstrictor actions of angiotensin II through either an increase in the expression of the AT1 receptor or changes in the post-receptor-mediated events within the vascular smooth muscle.

\section{Placental restriction and the renin-angiotensin system}

Intrafetal infusion of an angiotensin-converting enzyme inhibitor, captopril, decreased arterial blood pressure in growth restricted, but not normally grown, sheep fetuses after day 135 of gestation (Fig. 6) (Edwards et al., 1999). This finding indicates that the renin-angiotensin system (RAS) plays a greater role in the regulation of arterial blood pressure in placentally restricted than in normally grown sheep fetuses in late gestation. Captopril infusion did not alter the mean arterial blood pressure and peripheral blood flow changes during a 60 min period of fetal hypoxaemia (Green et al., 1998), but it did blunt the hypertensive response to hypoxia in sheep fetuses in which the carotid sinus nerves were cut (Green et al., 1998). Thus, once the carotid chemoreflex mechanisms were removed, there was a significant role for angiotensin II in the regulation of the blood pressure and peripheral blood flow responses to hypoxaemia. The functioning of the carotid chemoreflex mechanisms may be downregulated by the presence of a chronically low arterial $p \mathrm{O}_{2}$ in the placentally restricted fetus, and a role for circulating angiotensin II in the longterm regulation of mean arterial blood pressure may then emerge. It is also possible that prolonged hypoxaemia stimulates an increase in circulating angiotensin II. Alternatively, the increased circulating cortisol concentrations in the placentally restricted fetus may act to increase expression of the vasoactive angiotensin II receptor subtypes within the vascular smooth muscle and hence increase vascular responsiveness to angiotensin II. Therefore, the enhanced hypotensive response to captopril in the placentally restricted sheep fetuses during late gestation may be a consequence of an interaction between cortisol and the RAS. It is not known whether the enhanced hypotensive response to captopril persists after birth in this model. Treatment of the offspring of protein-restricted pregnant rats for 3 weeks with captopril abolished the increase in blood pressure normally present in this model in

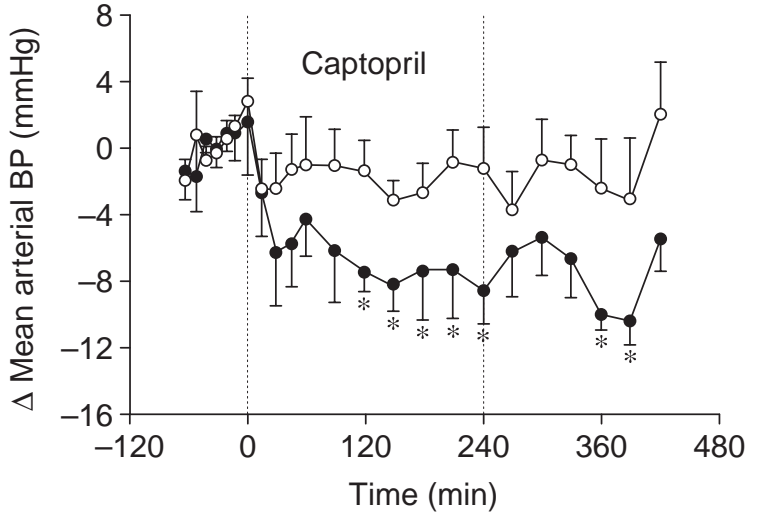

Fig. 6. Effect of an intravenous captopril infusion $\left(15 \mu \mathrm{g} \mathrm{min} \mathrm{m}^{-1}\right)$ on mean arterial blood pressure (BP) in control $(O ; n=6)$ and placentally restricted $(\mathbf{O} ; n=7)$ sheep fetuses between day 135 and day 145 of gestation. *Values significantly different from preinfusion values. (Redrawn from Edwards et al., 1999.)

the postnatal period. Thus, interactions between the effects of excess glucocorticoids and the RAS during the prenatal period may result in an increase in blood pressure in postnatal life that is independent of the source (maternal, fetal or species) of the increased fetal glucocorticoids.

\section{Glucocorticoids and the metabolic consequences of intrauterine growth restriction}

The actions of the increased plasma concentrations of glucocorticoids in fetal tissues in the growth-restricted fetus may be significantly modulated by the presence of the enzyme $11 \beta$-hydroxysteroid dehydrogenase (11ßHSD). There are two distinct isoforms of $11 \beta \mathrm{HSD}$ present in sheep and human fetal tissue during late gestation (Langlois et al., 1995; Yang et al., 1997). In sheep, 11ßHSD-2 acts as a dehydrogenase to convert cortisol to cortisone in the fetal kidney. In addition, the $\mathrm{NADP}(\mathrm{H})$-dependent isoform, $11 \beta \mathrm{HSD}-1$, is expressed in fetal liver, where it acts as a reductase to convert cortisone to cortisol (Funder et al., 1988). Although there are tissue-specific changes in the expression of $11 \beta \mathrm{HSD}-2 \mathrm{mRNA}$ in the adrenal gland and kidney of sheep fetuses during late gestation, there is no additional impact of placental and fetal growth restriction on 11ßHSD-2 mRNA expression in these tissues. In contrast, restriction of placental growth resulted in a twofold increase in $11 \beta \mathrm{HSD}-1 \mathrm{mRNA}$ expression in the liver of the growth-restricted sheep fetus (Fig. 7) (McMillen et al., 2000). Given the established relationship between $11 \beta$ HSD-1 mRNA expression and isoenzyme activity, it appears likely that there is an increase in 11ßHSD-1 reductase activity in the liver of the placentally restricted fetus. This finding indicates that there is increased hepatic exposure to cortisol in the growth-restricted fetus during late gestation, and this may have important pre- and postnatal consequences for the growth-restricted animal. There is a 


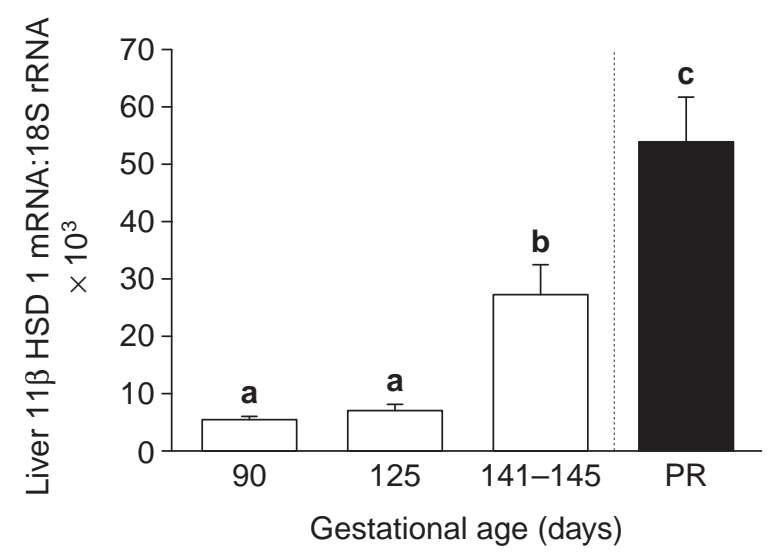

Fig. 7. Mean ( \pm SEM) expression of $3 \beta$-hydroxysteroid dehydrogenase $/ \Delta^{5}, \Delta^{4}$-isomerase (3$\beta$-HSD) type 1 mRNA: $18 \mathrm{~S}$ rRNA in the liver of normally grown sheep fetuses $(\square)$ at days 90, 125 and $141-145$ of gestation and in placentally restricted sheep fetuses $(\boldsymbol{\square}$, PR) at days 141-145 of gestation. Values with different letters differ significantly $(P<0.05)$. (Redrawn from McMillen et al., 2000.)

progressive increase in glycogen deposition and gluconeogenesis in the liver of sheep fetuses during late gestation, and circulating cortisol concentrations correlate positively with the activity of the hepatic gluconeogenic enzyme, phosphoenolpyruvate carboxykinase (PEPCK), in late gestation (Fowden et al., 1993). Furthermore, the induction of gluconeogenic enzyme expression is reduced in mice with a targeted disruption of the $11 \beta \mathrm{HSD}-1$ gene (Kotelevtsev et al., 1997). Thus, the increase in intrahepatic $11 \beta \mathrm{HSD}-1$ expression in sheep fetuses in late gestation and in growth-restricted fetuses may play a role in glucocorticoid-mediated increases in glycogen deposition and gluconeogenesis in the liver that occur immediately before birth and which may be important for fetal survival after a period of intrauterine substrate deprivation. In growth-restricted fetuses, intrahepatic exposure to excess glucocorticoids may also be important in the context of epidemiological evidence of an association between growth restriction in utero and non-insulin-dependent diabetes (Barker, 1998). Treatment of pregnant rats with dexamethasone in late pregnancy resulted in an increased hepatic expression of glucocorticoid receptor (GR) and PEPCK mRNAs, an associated increase in hepatic PEPCK activity and fasting hyperglycaemia in the adult offspring (Nyirenda et al., 1998). Since PEPCK is the rate-limiting enzyme of gluconeogenesis, the increased hepatic PEPCK expression may result in an increased hepatic glucose production and impaired glucose tolerance (Nyirenda et al., 1998). However, in these studies, dexamethasone treatment of the pregnant rat did not alter hepatic $11 \beta \mathrm{HSD}-1 \mathrm{mRNA}$ expression in the newborn or adult offspring, in contrast to the increase in hepatic $11 \beta \mathrm{HSD}-1$ mRNA concentrations in sheep fetuses placentally restricted in late gestation. Thus, although the mechanisms by which excess glucocorticoids act on the immature liver may differ depending on the nature of the glucocorticoid (synthetic versus endogenous) and species (rats versus sheep or humans), the outcomes in later life, including a persistent increase in hepatic gluconeogenic enzyme expression and glucose production, may be similar.

\section{Conclusion}

Further clarification of the molecular and cellular mechanisms underpinning the physiological adaptations of the fetus to a reduced substrate supply is required. The relative contributions of hypoxaemia and hypoglycaemia in the stimulation of the sympathoadrenal and hypothalamopituitary-adrenal axes when placental growth and function are restricted are not understood and there are limited data on the relative roles of the peripheral and central mechanisms that sense and respond to alterations in fetal substrate supply. For instance, it is unclear whether the carotid chemoreflex is up- or downregulated during placental restriction. The impact of hypoxaemia on angiogenesis and vascular branching during the development of fetal and placental circulations needs to be defined. It remains to be determined whether chronic hypoxaemia is associated with a hyperinnervation of the vasculature in placentally restricted fetuses. Finally, a detailed investigation of the interaction among the endogenously derived glucocorticoids, the renin-angiotensin system and vasoactive compounds, including noradrenaline and nitric oxide, within different regional circulations of the placentally restricted fetus remain to be carried out. Such mechanistic studies are required to determine how physiological adaptations promote the short-term survival of the fetus and newborn while predisposing the individual to adult hypertension, cardiovascular and metabolic disease.

\section{References}

Key references are identified by asterisks.

Adams MB, Phillips ID, Simonetta G and McMillen IC (1998) Differential effects of increasing gestational age and placental restriction on tyrosine hydroxylase, phenylethanolamine $\mathrm{N}$-methyltransferase, and proenkephalin A mRNA levels in the fetal sheep adrenal Journal of Neurochemistry 71 394-401

Anwar MA, Schwab M, Poston L and Nathanielsz PW (1999) Betamethasone-mediated vascular dysfunction and changes in hematological profile in the ovine fetus American Journal of Physiology $276 \mathrm{H} 1137-\mathrm{H} 1143$

Barker DJP (1992) Fetal and Infant Origins of Adult Disease British Medical Journal, London

Barker DJP (1998) Mothers, Babies and Health in Later Life Churchill Livingstone, Edinburgh

Barker DJP (1999) Fetal programming and public health. In Fetal Programming Influences on Development and Disease in Later Life pp 3-11 Eds PMS O'Brien et al. Royal College of Obstetrics and Gynaecology Press, London

Barker DJP, Bull AR, Osmond C and Simmonds SJ (1990) Fetal and placental size and risk of hypertension in adult life British Medical Journal $301259-262$ 
Block BS, Schlafer DH, Wentworth RA, Kreitzer LA and Nathanielsz PW (1990) Regional blood flow distribution in fetal sheep with intrauterine growth retardation produced by decreased umbilical placental perfusion Journal of Developmental Physiology 13 81-85

Bocking AD, Gagnon R, White SE, Homan J, Milne KM and Richardson BS (1988) Circulatory responses to prolonged hypoxaemia in the fetal sheep American Journal of Obstetrics and Gynecology 159 1418-1424

Boyle DW, Lecklitner S and Liechty EA (1996) Effect of prolonged uterine blood flow reduction on fetal growth in sheep American Journal of Physiology 270 R246-R253

Braems GA, Han VKM and Challis JRG (1998) Gestational age-dependent changes in the levels of mRNAs encoding cortisol biosynthetic enzymes and IGF-II in the adrenal gland of fetal sheep during prolonged hypoxaemia Journal of Endocrinology 159 257-264

Clapp JF, Szeto HH, Larrow R, Hewitt J and Mann LI (1981) Fetal metabolic response to experimental placental vascular damage American Journal of Obstetrics and Gynecology 140 446-451

Coulter CL, McMillen IC, Robinson JS and Owens JA (1998) Placental restriction alters adrenal medullary development in the midgestation sheep fetus Pediatric Research 44 656-662

Daniel SS, Stark RI, Myers MM, Tropper PJ and Young-Ih IK (1996) Blood pressure and HR in the fetal lamb: relationship to hypoglycemia, hypoxemia, and growth restriction American Journal of Physiology 271 R1415-R1421

Derks JB, Guissani DA, Jenkins SL, Wentworth RA, Visser GHA, Padbury JF and Nathanielsz PW (1997) A comparitive study of cardiovascular, endocrine and behavioural effects of betamethasone and dexamethasone administration to fetal sheep Journal of Physiology (London) 499 217-226

Economides DL, Nicolaides KH, Linton EA, Perry LA and Chard T (1988) Plasma cortisol and adrenocorticotropin in appropriate and small for gestational age fetuses Fetal Therapeutics 3 158-164

Economides DL, Nicolaides KH and Campbell S (1991) Metabolic and endocrine findings in appropriate and small for gestational age fetuses Journal of Perinatal Medicine 19 97-105

*Edwards LJ, Simonetta G, Owens JA, Robinson JS and McMillen IC (1999) Restriction of placental and fetal growth in sheep alters fetal blood pressure responses to angiotensin II and captopril Journal of Physiology (London) 515 897-904

Flanagan DE, Vaile JC, Petley GW, Moore VM, Godsland IF, Cockington RA, Robinson JS and Phillips DI (1999) The autonomic control of heart rate and insulin resistance in young adults Journal of Clinical Endocrinology and Metabolism 84 1263-1267

Forhead AJ, Broughton-Pipkin F and Fowden AL (2000) Effect of cortisol on blood pressure and the renin-angiotensin system in fetal sheep during late gestation Journal of Physiology(London) 526 167-176

Fowden AL, Mijovic J and Silver M (1993) The effects of cortisol on hepatic and renal gluconeogenic enzyme activities in the sheep fetus during late gestation Journal of Endocrinology 137 213-222

Funder JW, Pearce PT, Smith R and Smith AI (1988) Mineralocorticoid action target tissue specificity is enzyme, not receptor, mediated Science 242 583-585

Gagnon R, Challis J, Johnston L and Fraher L (1994) Fetal endocrine responses to chronic placental embolization in the late-gestation ovine fetus American Journal of Obstetrics and Gynecology 179 929-938

Giussani DA, Spencer JAD, Moore PJ, Bennet L and Hanson MA (1993) Afferent and efferent components of the cardiovascular reflex responses to acute hypoxia in term fetal sheep Journal of Physiology (London) 461 431-449

Giussani DA, Spencer JAD and Hanson MA (1994) Fetal cardiovascular reflex responses to hypoxaemia Fetal and Maternal Medicine Review $\mathbf{6}$ $17-37$

Green LR, McGarrigle HHG, Bennet L and Hanson MA (1998) Angiotensin II and cardiovascular chemoreflex responses to acute hypoxia in late gestation fetal sheep Journal of Physiology (London) 507 857-867

*Hoet JJ and Hanson MA (1999) Intrauterine nutrition its importance during critical periods for cardiovascular and endocrine development Journal of Physiology (London) 514 617-627

*Huxley RR, Sheill AW and Law CM (2000) The role of size at birth and postnatal catch-up growth in determining systolic blood pressure: a systematic review of the literature Journal of Hypertension 18 815-831

Jansen AH, Belik J, Ioffe S and Chernick V (1989) Control of organ blood flow in fetal sheep during normoxia and hypoxia American Journal of Physiology $257 \mathrm{H} 1132-\mathrm{H} 1139$

Jensen A, Hohmann M and Kunzel W (1987a) Dynamic changes in organ blood flow and oxygen consumption during acute asphyxia in the fetal sheep Journal of Developmental Physiology 9 325-326

Jensen A, Hohmann M and Kunzel W (1987b) Redistribution of fetal circulation during repeated asphyxia in sheep: effects on skin blood flow, transcutaneous $\mathrm{pO}_{2}$, and plasma catecholamines Journal of Developmental Physiology 9 41-55

Jones CT, Roebuck MM, Walker DW and Johnston BM (1988) The role of the adrenal medulla and peripheral sympathetic nerves in the physiological response to hypoxia Journal of Developmental Physiology 10 17-36

Kempley ST, Gamsu HR, Vyas S and Nicolaides K (1991) Effects of intrauterine growth retardation on postnatal visceral and cerebral blood flow velocity Archives of Disease in Childhood 66 1115-1118

Knutzen VK and Sher G (1982) The major determinants of perinatal mortality in a large metropolitan hospital: results of a retrospective study Journal of Reproductive Medicine 27 395-400

Kotelevtsev Y, Holmes MC, Burchell A, Houston PM, Schmoll D, Jamieson P, Best R, Brown R, Edwards CRW, SeckI JR and Mullins JJ (1997) $11 \beta$ hydroxysteroid dehydrogenase type 1 knockout mice show attenuated glucocorticoid inducible responses and resist hyperglycaemia on obesity or stress Proceedings of the National Academy of Sciences USA 94 14 924-14 929

Lafeber HN, Rolph TP and Jones CT (1985) Studies on the growth of the fetal guinea pig. The effects of ligation of the uterine artery on organ growth and development Journal of Developmental Physiology 6 441-459

Langley-Evans SC (1997) Maternal carbenoxolone treatment lowers birthweight and induces hypertension in the offspring of rats fed a protein-replete diet Clinical Science 93 423-429

*Langley-Evans SC, Phillips GJ, Gardener DS and Jackson AA (1996) Role of glucocorticoids in programming of maternal diet-induced hypertension in the rat Journal of Nutrition and Biochemistry 7 173-178

Langlois DA, Matthews SG, Yu M and Yang K (1995) Differential expression of $11 \beta$ hydroxysteroid dehydrogenase 1 and 2 in the developing ovine fetal liver and kidney Journal of Endocrinology 147 405-411

Levitt NS, Lindsay RS, Holmes MC and SeckI JR (1996) Dexamethasone in the last week of pregnancy attenuates hippocampal glucocorticoid receptor gene expression and elevates blood pressure in the adult offspring in the rat Neuroendocrinology 64 412-418

Llanos AJ, Green JR, Creasy RK and Rudolph AM (1980) Increased heart rate response to parasympathetic and beta adrenergic blockade in growth-retarded fetal lambs American Journal of Obstetrics and Gynecology 136 808-813

McMillen IC, Warnes KE, Adams MB, Robinson JS, Owens JA and Coulter CL (2000) Impact of restriction of placental and fetal growth on expression of $11 \beta$ hydroxysteroid dehydrogenase type 1 and type 2 mRNA in the liver, kidney and adrenal of the sheep fetus Endocrinology 141 539-543

Murotsuki J, Gagnon R, Matthews SG and Challis JRG (1996) Effects of long-term hypoxemia on pituitary-adrenal function in fetal sheep American Journal of Physiology $271 \mathrm{E} 678-\mathrm{E} 685$

Murotsuki J, Challis JRG, Han VKM, Fraher J and Gagnon R (1997) Chronic fetal placental embolization and hypoxaemia cause hypertension and myocardial hypertrophy in fetal sheep American Journal of Physiology 272 R201-R207

Newton ER, Kennedy JL, Louis F, Cetrulo CL, Sbarra A and Feingold M (1987) Obstetric diagnosis and perinatal mortality American Journal of Perinatology 4 300-304

Nyirenda MJ, Lindsay RS, Kenyon CJ, Burchell A and SeckI JR (1998) Glucocorticoid exposure in late gestation permanently programs rat hepatic phosphoenolpyruvate carboxykinase and glucocorticoid receptor expression and causes glucose intolerance in adult offspring Journal of Clinical Investigation 10 2174-2181

Owens JA, Owens PC and Robinson JS (1989) Experimental growth 
retardation: metabolic and endocrine aspects. In Advances in Fetal Physiology Reviews in Honour of GC Liggins pp 263-286 Eds PD Gluckman et al. Perinatology Press, New York

Oyama K, Padbury J, Chappell B, Martinez A, Stein H and Humme J (1992) Single umbilical artery ligation-induced fetal growth retardation: effect on postnatal adaption American Journal of Physiology 263 E575-E583

Phillips ID, Simonetta G, Owens JA, Robinson JS, Clarke IJ and McMillen IC (1996) Placental restriction alters the functional development of the pituitary-adrenal axis in the sheep fetus during late gestation Pediatric Research 40 861-866

Robinson JS, Kingston EJ, Jones CT and Thorburn GD (1979) Studies on experimental growth retardation in sheep: the effect of removal of endometrial caruncles on fetal size and metabolism Journal of Developmental Physiology $1379-398$

Robinson JS, Jones CT and Kingston EJ (1983) Studies on experimental growth retardation in sheep: the effects of maternal hypoxaemia Journal of Developmental Physiology 5 89-100

Robinson JS, Owens JA and Owens PC (1994) Fetal growth and fetal growth retardation. In Textbook of Fetal Physiology pp 83-94 Eds GD Thorburn and R Harding. Oxford University Press, Oxford

Ross JT, Phillips ID, Simonetta G, Owens JA, Robinson JS and McMillen IC (2000) Differential effects of placental restriction on IGF-II, ACTH receptor and steroidogenic enzyme mRNA levels in the fetal sheep adrenal Journal of Neuroendocrinology 12 79-85

Rurak DW, Richardson BS, Patrick JE, Carmichael L and Homan J (1990) Blood flow and oxygen delivery to fetal organs and tissues during sustained hypoxaemia American Journal of Physiology 258 R1116-R1122

Seckl JR, Nyirenda MJ, Walker BR and Chapman KE (1999) Glucocorticoids and fetal programming Biochemistry Transactions 27 74-78

Seckl JR, Cleasby $\mathbf{M}$ and Nyirenda MJ (2000) Glucocorticoids, $11 \beta$ hydroxysteroid dehydrogenase, and fetal programming Kidney International 57 1412-1417

Segar JL, Bedell K, Page WV, Mazursky JE, Nuyt AM and Robillard JE (1995)
Effect of cortisol on gene expression of the renin-angiotensin system in fetal sheep Pediatric Research 37 741-746

Shaul PW, Cha CM and Oh W (1989) Neonatal sympathoadrenal response to acute hypoxia: impairment after experimental intrauterine growth retardation Pediatric Research 25 466-472

*Simonetta G, Rourke AK, Owens JA, Robinson JS and McMillen IC (1997) Impact of placental restriction on the development of the sympathoadrenal system Pediatric Research 42 805-811

Sug Tang A, Bocking AD, Brooks AN, Hooper S, White SE, Jacobs RA, Fraher LJ and Challis JRG (1992) Effects of restricting uteroplacental blood flow on concentrations of corticotrophin releasing hormone, adrenocorticotrophin, cortisol and prostaglandin $\mathrm{E}_{2}$ in the sheep fetus during pregnancy Canadian Journal of Physiology and Pharmacology 70 1396-1402

Tangalakis K, Lumbers ER, Moritz KM, Towstoless MK and Wintour EM (1992) Effect of cortisol on blood pressure and vascular reactivity in the ovine fetus Experimental Physiology 77 709-717

Unno N, Wong CH, Jenkins SL, Wentworth RA, King XY, Li C, Robertson SS, Smotherman WP and Nathanielsz PW (1999) Blood pressure and heart rate in the ovine fetus: ontogenic changes and effects of fetal adrenalectomy American Journal of Physiology 276 H248-H256

Walker AM, de Preu ND, Horne RSC and Berger PJ (1990) Autonomic control of heart rate differs with electrocortical activity and chronic hypoxaemia in fetal lambs Journal of Developmental Physiology 14 43-48

Wood CE, Cheung CY and Brace RA (1987) Fetal heart rate, arterial pressure, and blood volume responses to cortisol infusion American Journal of Physiology 253 R904-R909

Yaffe H, Parer JT, Block BS and Llanos AJ (1987) Cardiorespiratory response to graded reductions of uterine blood flow in the sheep fetus Journal of Developmental Physiology 9 325-336

Yang K, Langlois DA, Campbell LE, Challis JR, Krkosek M and Yu M (1997) Cellular localization and developmental regulation of $11 \beta$ hydroxysteroid dehydrogenase type 1 (11 beta HSD1) gene regulation in the ovine placenta Placenta 18 503-509 